\title{
Research on Photovoltaic Array Characteristics with Partial Shadow
}

\author{
Zhonghua Yun a, Lijuan Zhu, Zhifeng Jiang, Liqiang Yan \\ School of Engineering, Tibet University, Lhasa 850012, China \\ aMicrofisher@163.com
}

\begin{abstract}
Keywords: PV array, MATLAB, Experiment, Partial shading.
\end{abstract}
\begin{abstract}
In order to study the working characteristics of PV system under different working conditions, in this paper we analyze and simulate the model based on the mathematical model of photovoltaic cells and the output characteristics of PV arrays under different illumination and temperature. We also study the output characteristics of the monolithic components of the PV array, and analyze the output voltage, current and power output in different lighting conditions in theoretically. The experiment selects different occlusion method for photovoltaic cells in series array, and results are in agreement with the simulation results. This paper has practical significance for photovoltaic systems engineering.
\end{abstract}

\section{Introduction}

In recent years, with the rapid consumption of the world's energy, new energy development has been more and more mentioned. In a variety of new energy sources, solar energy can be used as an inexhaustible clean energy which attracted more and more people. Photovoltaic power generation is an important way of solar energy utilization, which using semiconductor photovoltaic effect to convert solar energy into electricity, could provide people with a good clean energy. But the photovoltaic cells are susceptible to environmental such as temperature and light intensity ${ }^{[1-2]}$ etc. In order to research the working characteristics of photovoltaic cells in different working environments, we analyzes the mathematical simulation based on the mathematical model of PV, studying the output characteristics of photovoltaic cells in different lighting conditions. Analysis shows the relationship between the output voltage, the current and the power with the irradiation intensity in theoretically. The simulation results are verified by physical experiments

\section{Simulation of PV Model \& Experiment Analysis}

\subsection{Mathematical Model of Photovoltaic Battery}

The principle of photovoltaic cells for solar power is its photovoltaic effect. The equivalent circuit shows in Fig.1. In Fig. $1, \mathrm{I}_{\mathrm{ph}}$ is the photo-current, $\mathrm{I}_{\mathrm{d}}$ is the reverse saturation current, $\mathrm{R}_{\mathrm{S}}$ is the equivalent series resistance of the PV cell, $\mathrm{R}_{\mathrm{sh}}$ is the equivalent parallel resistance, $\mathrm{V}$ is the output voltage and $\mathrm{I}$ is the output current. According to Kirchhoff's law the mathematical model of the photovoltaic cell can be expressed by Eq.(1). In the equation, $\mathrm{A}$ is the $\mathrm{PN}$ junction factor, $\mathrm{T}$ is the absolute temperature, $\mathrm{q}$ is the electron charge, $\mathrm{K}$ is the Boltzmann constant ${ }^{[2-4]}$. When considering the fact that the parallel resistance $R_{s}$ in the engineering practice is approximately infinite, the latter term of the equation 1 can be ignored.

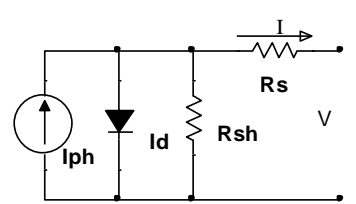

Fig.1 Schematic diagram of photovoltaic cells

$$
I=I_{p h}-I_{D}\left\{\exp \left[\frac{q\left(V+I R_{s}\right)}{A k T}\right]-1\right\}-\frac{V+I R_{s}}{R_{s h}}
$$

In iterature [5], the simplified model of photovoltaic cells has shown below by Eq.(2). 


$$
\left\{\begin{array}{l}
I=I_{s c}\left\{1-C_{1}\left[\exp \left(V / C_{2} V_{o c}\right)-1\right]\right\} \\
C_{2}=\left[\left(V_{m} / V_{o c}\right)-1\right] / \ln \left[1-\left(I_{m} / I_{s c}\right)\right] \\
C_{1}=\left[1-\left(I_{m} / I_{o c}\right)\right] \exp \left[-V_{m} /\left(C_{2} V_{o c}\right)\right]
\end{array}\right.
$$

Because of the uncertain working environment of photovoltaic cells, its output characteristics would change accordingly. Studies have given the formula for any light and temperature $\mathrm{I}_{\mathrm{sc}}, \mathrm{V}_{\mathrm{oc}}, \mathrm{I}_{\mathrm{m}}$, $\mathrm{V}_{\mathrm{m}}{ }^{[5-7]}$ such as Eq.(3).

$$
\left\{\begin{array}{l}
I_{s c}=I_{\text {scref }} * S / S_{r e f} *(1+a \Delta T) \\
V_{o c}=V_{o c r e f} \ln (e+b \Delta S)(1-c \Delta T) \\
I_{m}=I_{\text {mref }} * S / S_{r e f} *(1+a \Delta T) \\
V_{m}=V_{\text {mref }} \ln (e+b \Delta S)(1-c \Delta T)
\end{array}\right.
$$

In formulas, $\mathrm{S}_{\text {ref }}$ and $\mathrm{T}_{\text {ref }}$ represent the solar radiation and temperature standard test conditions (light intensity $1 \mathrm{KW} / \mathrm{m}^{2}$ and temperature $25{ }^{\circ} \mathrm{C}$ ), $\Delta \mathrm{S}=\mathrm{S}-\mathrm{S}_{\text {ref }}$ is the difference between the actual light intensity and the reference light intensity, $\Delta \mathrm{T}$ is the actual battery temperature and the reference temperature difference, $\mathrm{a}, \mathrm{b}, \mathrm{c}$ for the compensation coefficient. According to the literature [8] we can deduce that the change in the value of the characteristic curve at any light intensity and temperature as shown in Eq.(4).In the formula, $\Delta \mathrm{I}$ is the amount of change in current, $\Delta \mathrm{V}$ is the amount of change in voltage, $\alpha\left(\mathrm{A} /{ }^{\circ} \mathrm{C}\right)$ represents the current change temperature coefficient, $\beta\left(\mathrm{V} /{ }^{\circ} \mathrm{C}\right)$ represents the voltage change temperature coefficient

$$
\left\{\begin{array}{l}
\Delta I=\alpha\left(S / S_{r e f}\right) \Delta T+\left(S / S_{r e f}-1\right) I_{s c} \\
\Delta V=-\beta \Delta T-R_{s} \Delta I \\
\Delta T=T-T_{r e f}
\end{array}\right.
$$

In summary, The mathematical characteristics of the battery can be expressed as Eq.(5) after considering environmental changes

$$
I=I_{s c}\left\{1-C_{1}\left[\exp (V-\Delta V) / C_{2} V_{o c}-1\right]\right\}+\Delta I
$$

The simulink simulation selects GHGN-30WDJBZ monocrystalline silicon $30 \mathrm{~W}$ as components. The parameters of the component in the standard environment $\left(\mathrm{AM}=1.5, \mathrm{~T}=25^{\circ} \mathrm{C}, 1000 \mathrm{~W} / \mathrm{m}^{2}\right)$ are $\mathrm{V}_{\max }=17.6 \mathrm{~V}, \mathrm{I}_{\max }=1.7 \mathrm{~A}$, open circuit voltage $\mathrm{V}_{\mathrm{oc}}=21.6 \mathrm{~V}$, short circuit current $\mathrm{I}_{\mathrm{sc}}=1.95 \mathrm{~A}$, Open circuit voltage temperature coefficient of $-0.29 \%{ }^{\circ} \mathrm{C}$, short circuit current temperature coefficient of $0.05 \%{ }^{\circ} \mathrm{C}$. The Matlab simulation output waveform shows in Fig.2. In this figure, the unit of solar irradiance is $\mathrm{W} / \mathrm{m}^{2}$ and the temperature is in degrees Celsius ${ }^{\circ} \mathrm{C}$.
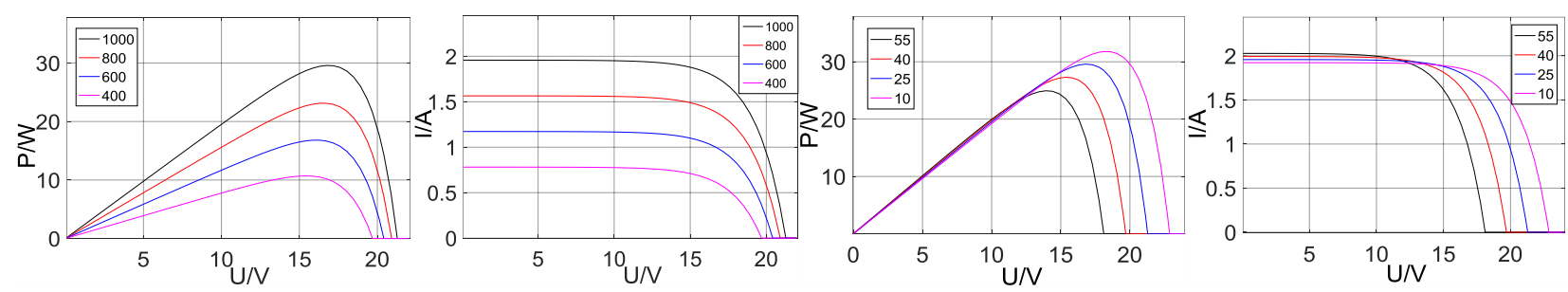

Fig. 2 output characteristics of PV

From the simulation result we can see that with the increase of solar irradiance, the output curve and power curve of the PV cell increases and with the increase of the temperature, the output curve decrease and the current curve decreases slightly.

In order to analyze the operating characteristics of PV modules under partial shadows, we conduct occlusion experiments. The scheme of the occlusion experiment is using different sizes of cardboard to block the battery piece of PV component one by one and gradually increase the number of the batteries that are blocked until the 36 cells of the battery panels are all blocked. After physical testing, we can see the output data in line with the simulation trend characteristic. The test result shows in Table. 1 and the practicality picture are shown in Fig.3. From the result we can see that the output 
characteristic curve conforms to the simulation waveform basically. And the above theoretical simulation can be verified.

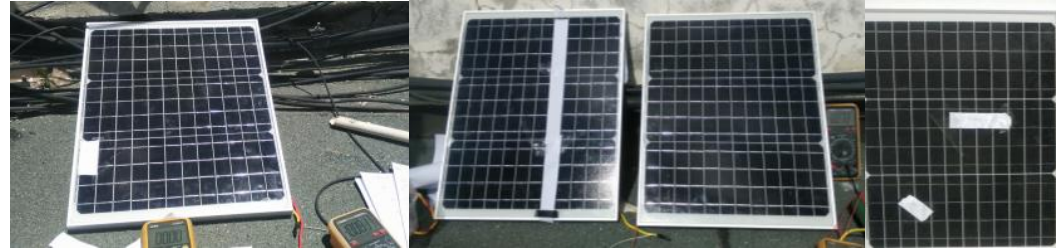

$\mathrm{a}$

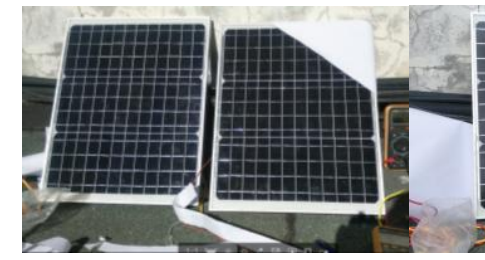

$\mathrm{e}$ b

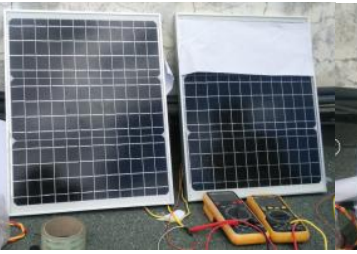

$\mathrm{f}$

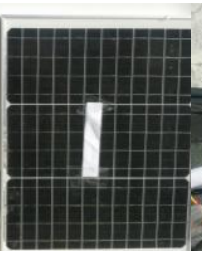

c

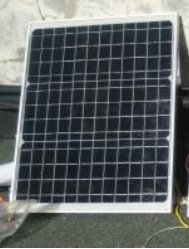

1

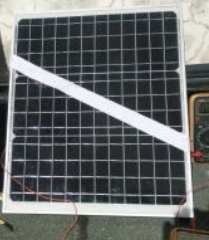

d

Fig.3 PV module experimental chart

The result data is fitted as a curve as shown in Fig.4.
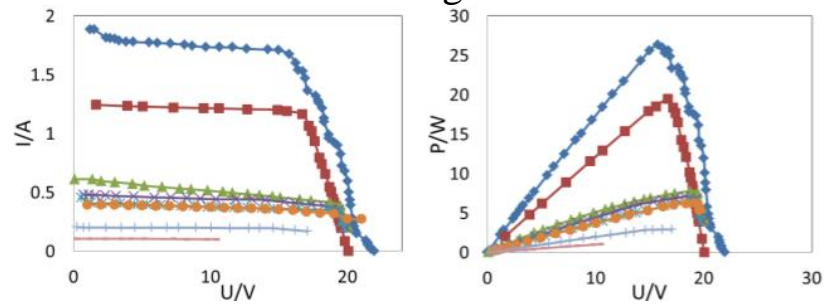

Fig.4 According to the measured data to fit out of the curve

We list the maximum voltage $V_{\max }$, the maximum current $I_{\max }$, and the $V_{m}, I_{m}, P_{m}$ of the maximum power point measured of the experiment in Table 1. The first column of the table indicates the number of cells that are blocked.

Table 1 single block of different occlusion experimental data

\begin{tabular}{|c|c|c|c|}
\hline & Vm & $\operatorname{Im}$ & Pm \\
\hline 0 & 15.74 & 1.676 & 26.38024 \\
\hline 0.5 & 16.69 & 1.168 & 19.49392 \\
\hline 1 & 18.75 & 0.416 & 7.8 \\
\hline 3 & 18.27 & 0.388 & 7.08876 \\
\hline 4 & 19.14 & 0.344 & 6.58416 \\
\hline 5 & 19.13 & 0.328 & 6.27464 \\
\hline 6 & 16.2 & 0.181 & 2.9322 \\
\hline
\end{tabular}

From Figure 4 and Table 1 we can conclude that when the occlusion area increases, the output current of the PV array will reduce, while the output voltage will gradually decrease, as well as its output power. The output current is already very small when the 6 of the 36 is blocked. If there is more obstruction, it can be considered that the battery components is no longer working. The result curve accords with the trend of simulation curve.

\subsection{Experiment of PV Array Under Different Shadow}

Because in the actual work, the light conditions that the Photovoltaic arrays may accept will be different, which causing a different output characteristics. In this paper we choose two components in series as an example and use different shading ways like 3, $4 \ldots$ and larger scale situation. In order to research under different shadows, we design seven different types' occlusions as shown in Fig. 3bFig. 3h. Adjust the output current from the open current to short circuit current. Due to the large amount of data, we only list part of the measurement data. We put the data in Matlab to fit the data into a curve to get its work characteristic trend to analysis. The experimental data are shown in Table 2. The data of the 7 sets of data are fitted into the curves as shown in Fig 5. 
It can be seen from Table 2 and Fig. 5 that the curves of the seven occlusion schemes are quite different, some appeared a multi-peak phenomenon, and some did not appear multi-peak, the maximum power point of the PV array under different shading conditions is completely different, we usually want the PV array to work with the maximum power point, so the array need for load matching to make the PV array in the optimal working condition.

Table 2. Experimental data according to Fig.5

\begin{tabular}{|c|c|c|c|}
\hline & Vm & Im & Pm \\
\hline b & 14.49 & 1.677 & 24.29973 \\
\hline c & 35.16 & 0.911 & 32.03076 \\
\hline d & 32.33 & 1.558 & 50.37014 \\
\hline e & 12.63 & 1.637 & 20.67531 \\
\hline f & 15.8 & 1.72 & 27.176 \\
\hline g & 37.14 & 0.451 & 16.75014 \\
\hline h & 32 & 1.497 & 47.904 \\
\hline
\end{tabular}

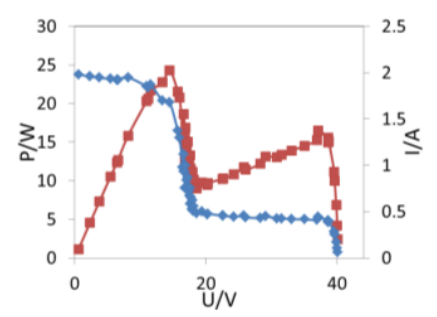

$\mathrm{b}$

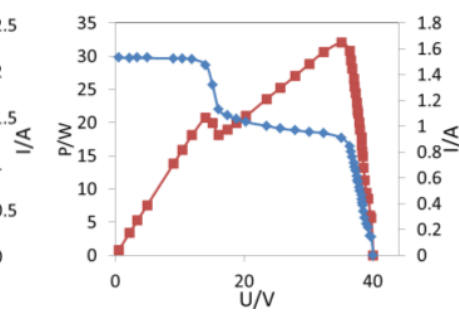

C

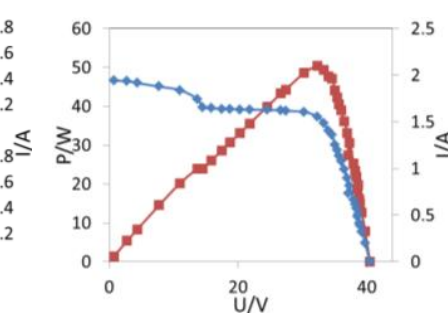

d

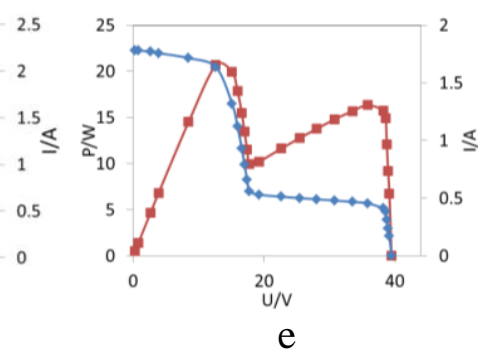

$\mathrm{e}$
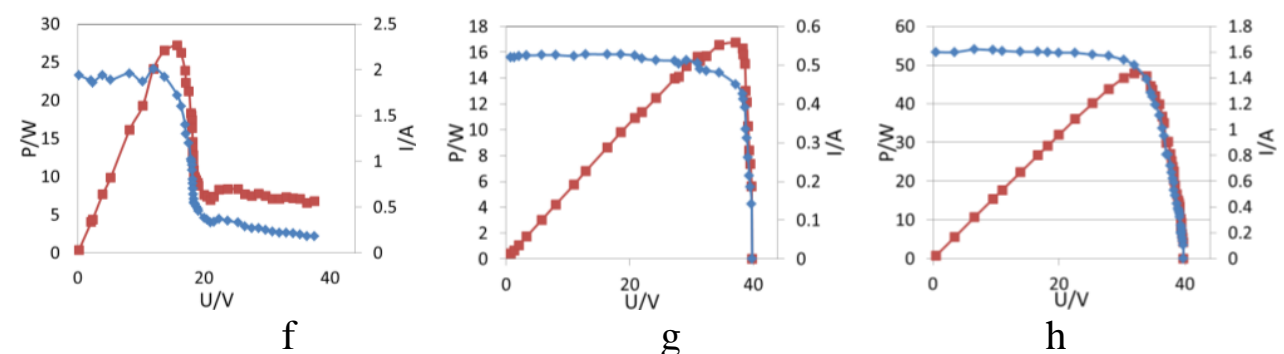

Fig.5 according to the measured data to fit out of the curve

It can be seen from Table 2 and Fig. 5 that the curves of the seven occlusion schemes are quite different, some appeared a multi-peak phenomenon, and some did not appear multi-peak, the maximum power point of the PV array under different shading conditions is completely different, we usually want the PV array to work with the maximum power point, so the array need for load matching to make the PV array in the optimal working condition.

\section{Output Power Analysis of Series Array Under Partial Shadows}

But in the daily work, components cannot be completely consistent. And the acceptance of the irradiance of PV cell module is not exactly the same. If a piece of battery components received less irradiance, the photogenerated current is also smaller. When the photogenerated current is less than the array output current, the component will become a load and consume energy. At this time the component will likely generate heat and produce hot spots. As the output of the PV module is usually parallel to a bypass diode to avoid hot spot effect ${ }^{[9-13]}$, we can assume that one or some of the batteries in the shadow caused the output current of the array $\mathrm{I}_{\mathrm{x}}<\mathrm{I}_{\text {out. }}$. At this time the output voltage exhibits a reverse voltage due to the internal resistance of the battery. As shown in Fig.6, this time the array will loses the output energy of this battery because the bypass diode turns on. The array output characteristics shows below by Eq.(6). 


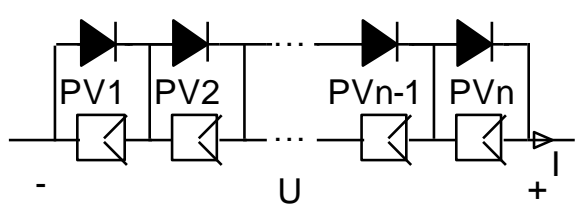

Fig.6 There are n components in series

$$
\begin{aligned}
& \left\{\begin{array}{l}
V_{\text {out }}=V_{1}+V_{2}+\cdots V_{\mathrm{n}} \\
P_{\text {out }}=P_{1}+P_{2}+\cdots P_{\mathrm{n}} \\
V_{\text {out }}=V_{1}+V_{2}+\cdots V_{\mathrm{n}}-V_{x} \\
P_{\text {out }}=P_{1}+P_{2}+\cdots P_{\mathrm{n}}-P_{x}
\end{array}\right\} 0<I_{\text {ou }}<I_{\text {wati }}
\end{aligned}
$$

When one block in a series array was under shadow, the array will lose part of the energy of this component. Also taking the serial array of 2 components as an example, assuming that one block of the array received solar irradiance. Simulations are performed from $100 \mathrm{~W} / \mathrm{m}^{2}$ to $1000 \mathrm{~W} / \mathrm{m}^{2}$, respectively, the output characteristics are shown in Fig.7.
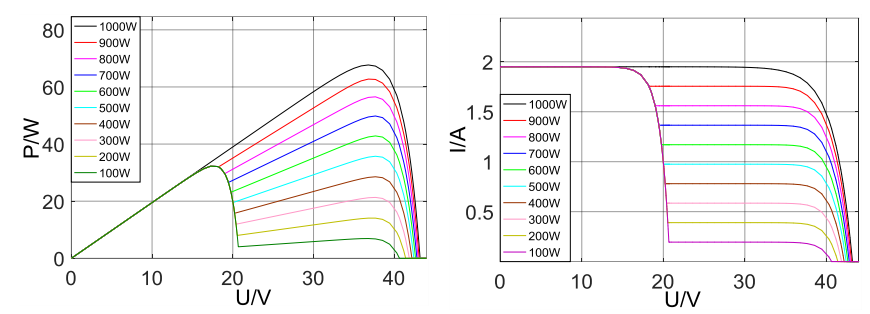

Fig.7 The output of a monolithic component at different intensities of irradiance

From Fig.7, we can conclude that, as one of the two batteries receives a reduction of solar irradiance, the output current of it also decreases, same as the output power. And the shift of the maximum power point occurs. If we want to make the array work with the maximum power point under the weaker solar irradiance, we must use the load matching method to reduce the operating voltage of the array by about twice. But at this time the capability of the array with the load voltage will be weakened.Set three arrays of components in series with different radiation intensity, respectively as (a): $762 \mathrm{~W} / \mathrm{m}^{2}, 518 \mathrm{~W} / \mathrm{m}^{2}, 279 \mathrm{~W} / \mathrm{m}^{2}$;(b): $352 \mathrm{~W} / \mathrm{m}^{2}, 716 \mathrm{~W} / \mathrm{m}^{2}, 431 \mathrm{~W} / \mathrm{m}^{2}$, (c): Each one is $1000 / \mathrm{m}^{2}$. The output characteristics of the simulation experiments shows in Fig 8.
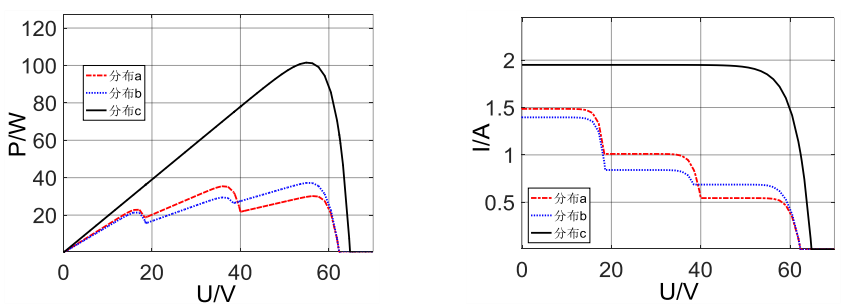

Fig.8 P-W \& I-A output characteristics of the curveUnder different light distribution

When we perform physical testing with different shades of shade, the output characteristics tend to conform to the simulation curve. Beacuse of the exposure of the PV array to sunlight and their own power generation problems, their temperature will rise a little. Therefore, the output characteristic trends approximately conform to the simulation curve.

\section{Conclusion}

Photovoltaic cells have different working characteristics in different environments, which show a strong non-linear. In this paper, we start from the mathematical model of photovoltaic cells, analysis of its parameters in different environments to correction the method and carries out the simulation experiment. The simulation results show that the output power of the PV cell increases with the increase of the solar irradiance, same as the output current. With the increase of temperature, the open 
circuit voltage has been reduced, and the short circuit current has been slightly reduced. Taking the serial array of 2 components as an example, we carries out the physical test experiment. Placing the PV array under different shadows to accept different light to test its output characteristics, which results show that the PV array has different working characteristics under different solar irradiance. Bypass diodes plays an important role in avoiding the hot spot effect. And we carry out the experiments on the working characteristics of photovoltaic cells at different intensities of sunlight. The experimental results verify its nonlinearity.

\section{Acknowledgement}

This work was supported by the Science Foundation of Tibet Autonomous Region (2016ZR-15-8); the innovation Support Program for Young Teachers of Universities in Tibet Autonomous Region (QCZ2016-26); the Youth Scientific Research Foundation of Tibet University (ZDPJZK1508) ; the National Natural Science Foundation of China (NSFC) ( 61640015).

\section{References}

[1] YZ Jia, LI Feng-Ting, H Zhu, HL Zhou. Effects of shadow on output characteristics of series PV array [J].Chinese Journal of Power Sources, 2014, (05): 844-846 + 854.

[2] LIU Bang-yin, DUAN Shan-xu, KANG Yong. Modeling and Analysis of characteristics PV Module with partial Shadow [J] . Acta Energiae Solaris Sinica, 2008, (02): 188-192.

[3] Silvestre S, Boronat A, Chouder A. Study of bypass diodes configuration on PV modules[J]. Applied Energy, 2009, 86(9):1632-1640

[4] HU Yi-hua, CHEN Hao, XU Rui-dong, ZAN Xiao-shu.PV Module Characteristics Effected by Shadow Problem [J] .Transactions of China Electrotechnical Society, 2011, (01): 123-128 + 134.

[5] Mao Meiqin, Yu Shijie, Su Jianhui. Versatile Matlab Simulation Model for Photovoltaic Array with MPPT Function [J]. Acta Simulata Systematica Sinica, 2005, (05): 1248-1251.

[6] Liu Xiaoyan, Qi Xinmei, Zheng Shusen, Wang Fei, Chen Daming.Model and Analysis of Photovoltaic Array under Partial Shading [J]. Power System Technology, 2010, (11): 192-197.

[7] Patel H, Agarwal V. Agarwal, V.: Maximum Power Point Tracking Scheme for PV Systems Operating Under Partially Shaded Conditions. IEEE Transactions on Industrial Electronics 55(4), 1689-1698[J]. IEEE Transactions on Industrial Electronics, 2008, 55(4):1689-1698.

[8] Su Jianhui,Yu Shijie,Zhao Wei,Wu Minda,Shen Yuliang,He Huiruo.investigation on engineering analytical model of silicon solar cells [J].Chinese Journal of Power Sources, 2001, (04): 409-412.

[9] Bressan M, Basri Y E, Galeano A G, et al. A shadow fault detection method based on the standard error analysis of I-V curves[J]. Renewable Energy, 2016, 99:1181-1190.

[10] Feng Zhicheng, Wang Yahui, Wu Lulu, Wang Zhaoyang, Wang Jingjing, Tian Rui. Experimental study on characteristics of pv module under partially shaded conditions [J].Acta Energiae Solaris Sinica, 2015, (02): 392-398.

[11] QI Jun, WENG Guo-qing, ZHANG Jing-hong.Multi-peak MPP distribution of photovoltaic array [J]. Electric Power Automation Equipment, 2014, (03): 132-137 + 143.

[12] ZHOU Di-qing, WU Chun-hua, LI Zhi-hua, FU Li, WANG Yuan-zhang.simulation and experimential Study of the photovoltaic modules under partial shading [J]. Acta Energiae Solaris Sinica, 2014, (11): 2098-2105.

[13] Forcan M, Željko Đurišić, Mikulović J. An algorithm for elimination of partial shading effect based on a Theory of Reference PV String[J]. Solar Energy, 2016, 132:51-63 